\title{
THE ANTIBACTERIAL ACTIVITY OF AQUEOUS EXTRACT OF CINNAMON AND CLOVE AGAINST STAPHYLOCOCCUS AUREUS.
}

\author{
Zainab A. Al-dhaher \\ Department of Basic Science, College of Dentistry, University of Baghdad.
}

\begin{abstract}
The antibacterial activity of aqueous extracts of cinnamon and clove against Staphylococcus aureus was investigated. Agar diffusion technique was applied in the trial. Both cinnamon and clove were found to have inhibitory effect against Staphylococcus aureus and the mean of the diameter of inhibition zones ranges from (7-17) $\mathrm{mm}$ for cinnamon and (7.5-19) $\mathrm{mm}$ for clove and statistical analysis using t-test demonstrated that there were significant differences between cinnamon and clove at each concentration used in this study in order that clove was found to have greater effects against Staphylococcus aureus. The minimum bactericidal concentration (MBC) was also determined and it was shown that $30 \%$ was the MBC for cinnamon and $15 \%$ was the MBC for clove.
\end{abstract}

Key words: - antibacterial activity, cinnamon, clove, Staphylococcus aureus.

\section{Introduction}

Staphylococcus aureus is a very common bacterium that lives on our skin and generally causes no trouble. But if it gets into the blood stream, through a cut or surgery. Staphylococcus aureus can very quickly damage the heart, lungs, brain or poison the entire system ${ }^{(1)}$ and it is an important cause of food poisoning ${ }^{(2)}$.

Microbial resistance to antibiotics especially among Staphylococcal strains is a major threat to public health ${ }^{(3)}$.

Therefore plant extract are suitable alternatives now to treat resistant organisms. Down the ages plants extracts have evoked interest as sources of natural products.

They have been screened for their potential uses as alternative remedies for the treatment of many infections diseases ${ }^{(4)}$. Plants extracts have been shown to posse's antibacterial, antifungal, antiviral, insecticidal and antioxidant properties (5), (6). Some plants extracts are used in food preservation ${ }^{(7)}$ as they are a rich source of biologically active compounds ${ }^{(8)}$. Plants extracts such as cinnamon and clove have been traditionally used by people for various purposes in different parts of the world.

Cinnamon and clove had shown antibacterial and antifungal activity cinnamon also posse's antidiabetic property ${ }^{(9)}$.

The present study was undertaken in order to evaluate the in-vitro antibacterial activity of cinnamon and clove aqueous extract against Staphylococcus aureus.

\section{Materials and methods}

Evaluation of antibacterial effects of two aqueous extracts (cinnamon, clove) against Staphylococcus aureus was done in this study.

The two aqueous extracts were prepared according to Cowans ${ }^{(10)}$.

Five diagnosed isolates of Staphylococcus aureus obtained from Baghdad teaching laboratories were used in the present study.

Staphylococcus aureus cultures of 18 hours at $37{ }^{\circ} \mathrm{C}$ in Mueller Hinton broth were used. The cultures were adjusted to approximately $10^{5} \mathrm{CFU} / \mathrm{ml}$ with sterile saline solution.

Agar diffusion technique was applied to study the antibacterial effect of the previously mentioned extracts.

Final concentration of $2.5 \%, 5 \%, 10 \%$, $15 \%, 20 \%, 30 \%, 40 \%, 50 \%, 60 \%$ and $70 \%$ of the aqueous extract of cinnamon and clove in Mueller agar were obtained for each extract separately.

Mueller Hinton agar plates were swabbed with a suspension of Staphylococcus aureus prepared as mentioned earlier, using sterile cotton swab. Plugs were removed from each agar plate producing holes. To each hole $100 \mu 1$ from different concentration of each extract was added and allowed to diffuse at room temperature for 20 minutes, the plates were then incubated aerobically overnight at 
$37{ }^{\circ} \mathrm{C}$. Determination of the minimum bactericidal concentration (MBC), the lowest concentration of the antimicrobial agent causing negative growth (fewer than three colonies) was done by serial dilution of Mueller Hinton broth and lineation of Mueller Hinton agar ${ }^{(11),(12) .}$

\section{Results and Discussions:-}

Each extract was tested against the five isolates of Staphylococcus aureus. The antibacterial activity of the extracts were recorded as the mean diameter of the resulting inhibition zones of growth measured in (millimeters). The antibacterial activity of cinnamon aqueous extract is summarized in Table (1).

The results revealed that cinnamon exhibited antibacterial activity against Staphylococcus aureus. As the mean of the diameter of inhibition zone were $(7 \mathrm{~mm})$, (8mm), (11 mm), (13mm), (15mm), (15.5mm), $(17 \mathrm{~mm})$ for the concentrations of $(15 \%)$, (20\%), (30\%), (40\%), (50\%), (60\%) and (70\%) respectively while the concentrations of $(2.5 \%), \quad(5 \%),(10 \%)$ did not give any inhibition zone.

The antimicrobial effect of medicinal plants is well documented ${ }^{(13)}$ and the results of different studies provide evidence that some medicinal plants might indeed be potential sources of new antibacterial agent even against some antibiotic-resistant strains of bacteria ${ }^{(14)}$.

In this current study using the agar diffusion technique it was observed that extract of cinnamon produce antibacterial activity against Staphylococcus aureus these results confirmed the observation of earlier studies of Fan et.al. (15), Yuste et.al. (16). Seeniva San et.al. (17) also reported that cinnamon showed potent and maximum activity among some plants extracts against Staphylococcus aureus.

The antibacterial activity of cinnamon has been attributed to the presence of some active constituents (18), (19). Cinnamaldehyde is the active compound in cinnamon and the earlier studies suggested that the antibacterial activity of cinnamon was probably due to this compound found in cinnamon and cinnamaldehyde is also a natural antioxidant $^{(20)}$.

Table(2) summarized the antibacterial activity of colve aqueous extract and the results showed that clove extract exhibited antibacterial activity against Staphylococcus aureus at nine of the ten concentrations used in this study and the mean of the diameter of inhibition zone were $(7.5 \mathrm{~mm}),(8 \mathrm{~mm})$, $(10 \mathrm{~mm}),(11 \mathrm{~mm}),(13 \mathrm{~mm}),(15 \mathrm{~mm})$, $(16.5 \mathrm{~mm}), \quad(17 \mathrm{~mm}),(19 \mathrm{~mm})$ for the concentrations of $(5 \%),(10 \%),(15 \%),(20 \%)$, $(30 \%),(40 \%),(50 \%),(60 \%),(70 \%)$ of clove respectively.

These results revealed that clove extract also exhibit antibacterial activity against Staphylococcus aureus.

This was in agreement with the results of Seeniva San et.al. ${ }^{(17)}$ who found that clove extract inhibit the growth of Staphylococcus aureus this was also reported by Agaoglu et.al. ${ }^{(21)}$ Hitokoto et.al. ${ }^{(22)}$. In another hand Burt et.al. ${ }^{(23)}$ reported that clove has antiseptic as well as bacteriostatic and bactericidal activity against Staphylococcus aureus.

The effect of clove may be explained by the action of eugenol and eugenol acetate contained in its volatile oils as many investigators have reported ${ }^{\text {(24)(25)(26). }}$.

Sensitivity of Staphylococcus aureus to different concentrations of cinnamon and clove extracts were tested separetly. As mentioned earlier both of them have antibacterial activity against Staphylococcus aureus. These results were also reported by Barbosa- Kanovas et.al. ${ }^{(27)}$ who showed that cinnamon and clove had a strong inhibitory activity against microorganisms.

Another study done by Fyfe et.al. ${ }^{(28)}$ demonstrated that cinnamon and clove significantly decreased the production of enterotoxin A and enterotoxin B of staphylococcus aureus.

The results of the present study using student t-test demonstrated that there are significant differences at $\mathrm{P}<0.05$ between cinnamon and clove for each concentration used in this study and this was demonstrated in Table (3). From these results we noticed that clove extract had greater effects than cinnamon extract at each concentration used on Staphylococcus aureus. 
This may be explained by the fact that extracts that contain eugenol have been show to exhibit the strongest antimicrobial activity (29) while Seeniva San et.al. ${ }^{(17)}$ Reported that cinnamon extract exhibit greater activity than clove on Staphylococcus aureus but both of them exhibit antibacterial activity against Staphylococcus aureus. The main factors that determine antibacterial activity are type, composition of the extract used, $\mathrm{pH}$ and temperature of the environment ${ }^{(30)}$. Table (4) showed the minimum bactericidal concentration $(\mathrm{MBC})$ of cinnamon and clove aqueous extract.

The results of this study demonstrated that the minimum bactericidal concentration (MBC) of cinnamon aqueous extract for Staphylococcus aureus was $30 \%$ the majority of Staphylococcus aureus isolates were sensitive at this concentration it seems to be toxic to these bacteria.

For clove aqueous extract the concentration of $15 \%$ was able to make all isolates or strains of Staphylococcus aureus sensitive at this concentration and it was considered the MBC

In conclusion cinnamon and clove were found to have important antibacterial activity against Staphylococcus aureus. In this regard, the use of them as natural preservatives in food products (to prevent food poisoning by Staphylococcus aureus) may be alternative of chemical additives they can be also incorporated into creams, lotion to treat diseased caused by Staphylococcus aureus.

Table (1)

Sensitivity of Staphylococcus aureus to different concentrations of cinnamon aqueous extract.

\begin{tabular}{|c||c||c|}
\hline $\begin{array}{c}\text { Conce.of } \\
\text { cinnamon }\end{array}$ & frequency & $\begin{array}{c}\text { Mean diameter of } \\
\text { inhibition zones (mm) }\end{array}$ \\
\hline \hline $70 \%$ & 5 & 17 \\
\hline \hline $60 \%$ & 5 & 15.5 \\
\hline \hline $50 \%$ & 5 & 15 \\
\hline \hline $40 \%$ & 5 & 13 \\
\hline \hline $30 \%$ & 5 & 11 \\
\hline \hline $20 \%$ & 5 & 8 \\
\hline $15 \%$ & 5 & 7 \\
\hline \hline $10 \%$ & 5 & 0 \\
\hline $5 \%$ & 5 & 0 \\
\hline \hline $2.50 \%$ & 5 & 0 \\
\hline
\end{tabular}

Table (2)

Sensitivity of Staphylococcus aureus to different concentrations of clove aqueous extract.

\begin{tabular}{|c||c||c||}
\hline $\begin{array}{c}\text { Conce. of } \\
\text { clove }\end{array}$ & frequency & $\begin{array}{c}\text { Mean diameter of } \\
\text { inhibition zones } \\
\text { (mm) }\end{array}$ \\
\hline \hline $70 \%$ & 5 & 19 \\
\hline \hline $60 \%$ & 5 & 17 \\
\hline \hline $50 \%$ & 5 & 16.5 \\
\hline $40 \%$ & 5 & 15 \\
\hline $30 \%$ & 5 & 13 \\
\hline \hline $20 \%$ & 5 & 11 \\
\hline \hline $15 \%$ & 5 & 10 \\
\hline \hline $10 \%$ & 5 & 8 \\
\hline \hline $5 \%$ & 5 & 7.5 \\
\hline \hline $2.50 \%$ & 5 & 0 \\
\hline
\end{tabular}

Table (3)

Comparison between cinnamon and clove aqueous extract for each test concentration in relation to the sensitivity of Staphylococcus aureus.

\begin{tabular}{|c|c|c|c|}
\hline $\begin{array}{c}\text { Percent } \\
\text { concentration }\end{array}$ & extracts & $\begin{array}{l}\text { Mean } \\
(\mathrm{mm})\end{array}$ & Sig. \\
\hline \multirow[t]{2}{*}{$5 \%$} & cinnamon & 0 & $\mathrm{~S}$ \\
\hline & clove & 7.5 & \\
\hline \multirow[t]{2}{*}{$10 \%$} & cinnamon & 0 & $\mathrm{~S}$ \\
\hline & clove & 8 & \\
\hline \multirow[t]{2}{*}{$15 \%$} & cinnamon & 7 & $\bar{S}$ \\
\hline & clove & 10 & \\
\hline \multirow[t]{2}{*}{$20 \%$} & cinnamon & 8 & $\mathrm{~S}$ \\
\hline & clove & 11 & \\
\hline \multirow[t]{2}{*}{$30 \%$} & cinnamon & 11 & $\bar{S}$ \\
\hline & clove & 13 & \\
\hline \multirow[t]{2}{*}{$40 \%$} & cinnamon & 13 & $\mathrm{~S}$ \\
\hline & clove & 15 & \\
\hline \multirow[t]{2}{*}{$50 \%$} & cinnamon & 15 & $\mathrm{~S}$ \\
\hline & clove & 16.5 & \\
\hline \multirow[t]{2}{*}{$60 \%$} & cinnamon & 15.5 & $\mathrm{~S}$ \\
\hline & clove & 17 & \\
\hline \multirow[t]{2}{*}{$70 \%$} & cinnamon & 17 & $\mathrm{~S}$ \\
\hline & clove & 19 & \\
\hline
\end{tabular}

S: Significant difference at level $P<0.05$. Mean: mean of diameter of inhibition zones. 
Table (4)

Minimum bactericidal concentrations (MBC) of cinnamon and clove aqueous extract for Staphylococcus aureus.

\begin{tabular}{|c|c|c|c|c|c|c|c|c|c|}
\hline type of & & No. & $f$ isola & es wi & in th & MBC & f ext & & \\
\hline extract & frequency & & $\%$ cor & entra & ions & & & & \\
\hline & & $5.00 \%$ & $10 \%$ & $15 \%$ & $20 \%$ & $25 \%$ & $30 \%$ & $35 \%$ & $40 \%$ \\
\hline cinnamon & 5 & 0 & 0 & 0 & 0 & 1 & 4 & 0 & 0 \\
\hline extract & & & & & & & & & \\
\hline clove & 5 & 0 & 0 & 5 & 0 & 0 & 0 & 0 & 0 \\
\hline extract & & & & & & & & & \\
\hline
\end{tabular}

\section{References}

[1] G. K. F.Elsom, and D. Hide: Susceptibility of methicillin-resistant Staphylococcus aureus to tea tree oil and mupirocin. $\mathrm{J}$ anti microb chemother,Vol. 43, No.1, 1999, pp. 427-428.

[2] Christian Janet and Greger Janet: Nutrition for Living. Benjamin/Cummings Publishing Company, Fourth Edition, U.S.A., 1994.

[3] G. A. Ayliffe: The progressive intercontinental spreads of methicillinresistant Staphylococcus aureus. Clin. Infect. Dis., Vol. 24, no. 1, 1997, pp. 574579.

[4] B Tepe, D Daferera , M Sokmen , M Polissiou, A. Sokmen : In vitro antimicrobial and antioxidant activities of the essential oils and various extracts of Thymus eigii M. Zohary et P.H. Davis. $J$ Agric Food Chem, Vol. 52, No. 3, 2004, pp. 1132-1137.

[5] SA Burt: Essential oils: their antibacterial properties and potential applications in foods: a review. Inter J Food Microbiol, Vol. 94, no.2, 2004, pp. 223-253.

[6] S Kordali , R Kotan, A Mavi, A Cakir , A Ala , A Yildirim : Determination of the chemical composition and antioxidant activity of the essential oil of Artemisia dracunculus and of the antifungal and antibacterial activities of Turkish Artemisia absinthium, A. dracunculus, Artemisia santonicum, and Artemisia spicigera essential oils. J Agric Food Chem, Vol. 53, No.3, 2005, pp. 9452-9458.

[7] M Faid, K Bakhy , M Anchad , A Tantaoui-Elaraki , Alomondpaste: Physicochemical and microbiological characterizations and preservation with sorbic acid and cinnamon. J Food Prod, Vol. 58, No. 5, 1995, pp. 547-550.

[8] G Milhau, A Valentin, F Benoit, M Mallie, J Bastide, Y Pelissier, Bessiere J.: In vitro antimicrobial activity of eight essential oils. J Essent Oil Res, Vol. 9, 1997, pp. 329-333.

[9] B Ouattara, RESimard, Holley RA, Pitte GJP, Begin A.: Antibacterial activity of selected fatty acids and essential oils against six meat spoilage organisms. $J$ Food Microbiol, Vol. 37, 1997, pp. 155162.

[10] M Cowan: Plant products as antimicrobial agents. Clinical Microbiology Reviews, Vol. 12, No. 4, 1999, pp. 564-582.

[11] A. L. Barry: The Antimicrobic Susceptibility Test, Principles and Practices. Lea and Febiger, Philadelphia 1976.

[12] A. Al-Mizrakchi: Adherence of Mutans streptococci on teeth surfaces, Microbiological and Biochemical studies, Phd thesis, University of Al-Mustansiriya, Iraq, 1998.

[13] M Valero and M. C. Salmeron: antibacterial activity of 11 essential oils against Bacillus cereus in tyndallized carrot broth. Int. J. Food microbial, Vol. 85, 2003, pp. 73-81.

[14] W. M. Kone, K. K. Atindehon, C. Terreaux, K. Hostettmann, D. Traore and M. Dosso: traditional medicine in north cote-dIvoire: screening of so plants for antibacterial activity. J. E thnopharmacol, Vol. 93, 2004, pp. 43-49.

[15] M. Fan and J. Chen: Studies on antimicrobial activity of extracts from 
thyme.wep Sheng Wu Xue Bao, Vol. 41, 2001, pp. 499-504.

[16] J. Yuste and D. Y. Fung: Inactivation of Salmonella typhimurium and Escherichia coli 0157: H7 in apple juice by a combination of nisin and cinnamon. J. Food Prot., Vol. 67, 2006, pp. 317-371.

[17] P. Seeniva San, J. Manickkam, I. Savarimuthu: In vitro Antibacterial Activity of Some Plants Essential Oils MBC Complementary and Alternative Medicine, Vol. 6, No. 11, 2006, pp. 147.

[18] G. Simic, M. Sokovic, M. Ristic, G. Grujic- Jovanovic, Vukojevic J,Marin PD: the chemical composition of some lauraceae essential oils and their antifungal activities. Phytotner Res., Vol. 18, 2004, pp. 713-717.

[19] M. T. Baratta, H J Dorman, S. G. Deans, A. C. Fig uereredo, J. G. Barroso, G. Ruberto: Antimicrobial and antioxidant properties of some commercial essential oil. Lav Fragr, Vol. 13, 1998, pp. 235-244.

[20] M. Blumenthal: the complete commission E monographs Therapeutic Guide Herbal Medicines, Boston, and Mass: Integrative Medicine Communications, 1998, pp. 110.

[21] S. Agaoglu,N. DosTbil and S. Alemi: antimicrobial activity of some spices used in the meat industry. Bull. Vet Inst Pulawy, Vol. 51, No. 5, 2007, pp. 53-57.

[22] H. Hitokoto, S. Morozumi, T. Wauke, S. Sakai, H. Kurata: Inhibitory effects of spices on growth and toxin production of toxigenic fungi, Vol. 39, 1980, pp. 818822.

[23] S. A. Burt and R. D. Reinders: Antibacterial activity of selected plant essential oils against Esherichia coli 0 157, H7.lett. Appl. Microbiol, Vol. 36, 2003, pp. 162-167.

[24] M. A. Azzouz, L. R. Bullerman: Comparative antimycotic effects of selected herbs and spices, plant components and commercial antifungal agents. J Food Port, Vol. 45, 1982, pp. 1248-1310.

[25] H. Hitokoto, S. Morozumi, T. Wauke, S. Sakai, H. Kurata: Inhibitory effects of spices on growth and toxin production of toxigenic fungi. Apple Environ Microbiol, Vol. 39, 1980, pp. 818-822.
[26] T. Katayama, N. Nagai: chemical significance of volatile components of spices in the food preservative viewpoint. VI. Structure and antibacterial activity of terpenes. Bull Japan Soc Sci Fish, Vol. 26, 1960, pp. 29-32.

[27] G.V. Barbosa-Canovas, V.R. Pothakamury, E. Paluo, B.G. Swanson: Non-thermal Preservation of Foods. Marcel Dekker Inc., New York, 1998.

[28] L. Fyfe: Antimicrobial agents and chemotherapy. Journal of Medical Microbiology, Vol. 53, No. 10, 2004, pp. 1023-1027.

[29] J. Kim, M.R. Marshall, C. Wei: Antibacterial activity of some essential oil components against five foodborne pathogens. J Agric Food Chem, Vol. 43, 1995, pp. 2839-2845.

[30] O. Sağdiç: Sensitivity of four pathogenic bacteria ot Turkish thyme and wild marjoram hydrosols. Lebensm Wiss Technol, Vol. 36, 2003, pp. 467-473. 